\title{
Blackberry pulp microencapsulation with arrowroot starch and gum arabic mixture by spray drying and freeze drying
}

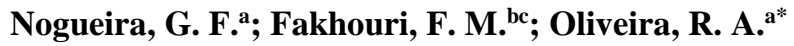 \\ a School of Agricultural Engineering, University of Campinas, Campinas, SP, Brazil \\ b School of Chemical Engineering, University of Campinas, Campinas, SP, Brazil \\ c School of Food Engineering, Federal University of Grande Dourados, Dourados, MS, \\ Brazil
}

*E-mail of the corresponding author: augustus@feagri.unicamp.br

\begin{abstract}
The objective of this research work was to obtain blackberry pulp powder (BL, without encapsulating agent) and microencapsulated blackberry pulp ( $M L$, with encapsulating agent :mixture of starch arrowroot and gum arabic (1:1)) obtained by freeze drying and spray drying and evaluate their physicochemical properties. The yield of blackberry freeze drying process was higher than the value found for spray drying process. The presence of encapsulating agent and drying method used for producing the powders influenced the average particle size, diameter, hygroscopicity, solubility, wettability and anthocyanin content of the powders.
\end{abstract}

Keywords: process yield; average size; hygroscopicity; solubility; anthocyanin; antioxidant property. 
Blackberry pulp microencapsulation with arrowroot starch and gum arabic mixture by spray drying and freeze drying

\section{Introduction}

Blackberry (Rubus fruticosus) cv. Tupy is a fruit rich in anthocyanins and phenolic compounds, which has high antioxidant activity.[1] However, its short shelf life, due to their fragility and high postharvest respiration rate, consists of an enormous challenge for agri-food industries. Application of microencapsulation by spray drying and freeze drying is a technique to maintain or increase the stability of blackberry pulp bioactive compounds and to prolong its shelf life.[2] More specifically, spray drying is a technological process in which a fluid product is transformed into powder by atomizing it into a hot gas stream.[3] Freeze drying is based on dehydration by sublimation of a frozen product resulting in a dry material.[4] Both processes can be used as encapsulation method when it incorporates 'active' material within a protective matrix, which is essentially inert to the material being encapsulated.[5] The arrowroot (Maranta arundinaceae L.) starch presents good digestibility [6] and gelling ability [7]. Gum arabic is widely used in food industry. It is nontoxic, odorless and tasteless. It interacts with water and has a wide range of applications, such as emulsification, texture control and flavor encapsulation.[8] Until now, no study used arrowroot starch and gum arabic mixture as encapsulating agent during spray drying or freeze drying. The objective of this research work was to obtain pulp blackberry in powder microencapsulated with mixture of starch arrowroot and gum arabic (1:1) by spray drying and freeze drying processes in order to evaluate the influence of different drying methods and presence of encapsulating agent on the physico-chemical properties of blackberry powders.

\section{Materials and Methods}

\subsection{Materials}

Frozen fruits of blackberry (Rubus fruticosus), cv Tupy, were acquired from "Agro Monte Verde Eirelli", Cambuí - MG, Brazil, and used in this research work. Pulp was obtained by grinding of blackberry fruit in a blender, previously thawed in the refrigerator $\left(8^{\circ} \mathrm{C}\right)$ for 24 $\mathrm{h}$. Then, pulp was sieved to remove the seeds, homogenized and packed in polypropylene bottles and coated with aluminium foil to protect against photodegradation. The samples were stored in freezer at $-40 \pm 3{ }^{\circ} \mathrm{C}$ until drying process. Blackberry soluble solids content was $9{ }^{\circ}$ Brix, determined with a benchtop refractometer (Reichert, Model AR200, USA). The pulp presented total solids content of $10.3 \mathrm{~g} / 100 \mathrm{~g}$ of pulp.

The following encapsulating agents were used: arrowroot starch containing $15.24 \pm 0.19 \%$ of water, $0.40 \pm 0.03 \%$ of protein, $0.12 \pm 0.01 \%$ of fat, $0.33 \pm 0.01 \%$ of ash and $83.91 \pm$ $0.00 \%$ of carbohydrates [9]; and gum arabic (Instantgum ${ }^{\circledR}$, Colloides Naturels, São Paulo, Brazil) containing $14.00 \pm 0.10 \%$ of water, $1.38 \pm 0.16 \%$ of proteins, $0.37 \pm 0.02 \%$ of 
lipids, $3.70 \pm 0.10 \%$ of ash and $80.46 \pm 0.00 \%$ of carbohydrates.[9] All other reagents used for the analyses presented analytical grade.

\subsection{Preparation of blackberry pulp microparticles}

Blackberry microparticles were produced from homogenization of blackberry pulp with encapsulating agent, consisting of arrowroot starch and gum arabic mixture (1: 1 mass / mass) in ratio of 1:1.78 (mass / mass, blackberry pulp solids and encapsulating agent). Solution of encapsulating agent and blackberry pulp was performed in a mixer type homogenizer at room temperature for 5 minutes. Spray drying and freeze drying techniques were used to prepare blackberry pulp microparticles.

\subsubsection{Spray drying}

The freshly prepared solution of blackberry pulp and encapsulating agent (item 2.2) was diluted in water in proportion of 1:2 (w/ w) to enable its spraying. A benchtop spray dryer (Model B191, Büchi, Flawil, Switzerland) with feed mass flow rate of $0.2 \mathrm{~kg} / \mathrm{h}$ was used in the process. Atomization was accomplished using a $0.5 \mathrm{~mm}$ double-flow atomizer nozzle. Compressed air was used as atomizing media and the inlet and outlet air temperatures were $143{ }^{\circ} \mathrm{C}$ and $105.43 \pm 3.13{ }^{\circ} \mathrm{C}$, respectively. Compressed air flow rate was $0.6 \mathrm{~m}^{3} / \mathrm{h}$ and its pressure was maintained at 8 bar. Powders were collected at cyclone and finally transferred for polyethylene packages. These spray dried blackberry microparticles were stored in desiccator containing dried allochroic silica gel at $25{ }^{\circ} \mathrm{C}$.

\subsubsection{Vacuum freeze drying}

A portion of frozen blackberry pulp with and without encapsulating agent (item 2.2) was freeze dried (Mod. 501, Edwards Pirani, Crawley, West Sussex, UK), with initial temperature of $-40{ }^{\circ} \mathrm{C}$, pressure of $0.1 \mathrm{mmHg}$ and final temperature of $25{ }^{\circ} \mathrm{C}$ per $2 \mathrm{~h}$, with total cycle time of $48 \mathrm{~h}$. The product obtained was ground in hammer mill (MR Manesco and Ranieri LTDA, model MR020, Piracicaba- Brazil) and sieved. Freeze dried blackberry microparticles were stored in the same conditions of spray dried samples.

\subsection{Powder characterization}

2.3.1 Drying process yield, moisture content, water activity, hygroscopicity, solubility, wettability, particle size distribution of the blackberry powders 
Blackberry pulp microencapsulation with arrowroot starch and gum arabic mixture by spray drying and freeze drying

Drying process yield was determined by ratio between powder solids mass and feeding solids mass of blackberry pulp. The powder moisture content was gravimetrically obtained by vacuum oven at $60{ }^{\circ} \mathrm{C}$ until constant weight. [9] Water capacity was determined by direct reading at $25{ }^{\circ} \mathrm{C}$, using AquaLab Lite apparatus (Decagon Devices Inc., Pullman, USA).

Hygroscopicity was determined according to methodology proposed by Cai and Corke [10], with some modifications. About $1 \mathrm{~g}$ of each powder sample was placed in desiccators containing saturated sodium chloride $(\mathrm{NaCl})$ solution, equivalent to $75.7 \%$ relative humidity at $25{ }^{\circ} \mathrm{C}$. After one week, the samples were weighed in triplicate and hygroscopicity was expressed in grams of water absorbed per $100 \mathrm{~g}$ of solids dry mass of the sample (g / 100g).

Solubility was determined according to the method of Eastman and Moore (1984), cited by Cano-Chauca et al. [11]. The method consisted of adding $1 \mathrm{~g}$ of sample to a vessel containing $100 \mathrm{~mL}$ of distilled water, operating with high-speed magnetic stirring - level 4 of magnetic stirrer for 5 minutes, followed by centrifugation at $3000 \mathrm{G}$ for 5 minutes. Aliquot of $25 \mathrm{~mL}$ of supernatant was removed and brought to the oven at $105{ }^{\circ} \mathrm{C}$ until constant weight. The solubility was calculated by weight difference.

Wettability time was evaluated according to the method described by Hla and Hogekamp [12]. The method consisted in dropping of $1 \mathrm{~g}$ of powder over $400 \mathrm{~g}$ of distilled water at 25 ${ }^{\circ} \mathrm{C}$ in $600 \mathrm{~mL}$ beaker and visual measurement using a stopwatch to determine the time required for presence of powdered material on the water surface.

The particle size distribution was determined by a particle size analyzer based on laser diffraction (Mastersizer 2000, Malvern Instruments, UK). The mean diameter was determined based on the diameter of a sphere with equivalent volume (De Brouckere Mean Diameter, D[4.3]). Samples were analyzed in triplicate with dispersion in 99.5\% ethanol.

\subsubsection{Anthocyanins content}

Anthocyanins in powders were determined according to the method employed by Sims and Gamon [13] with adaptations. Samples were weighed in triplicate and homogenized with 3 $\mathrm{mL}$ of cold solution of acetone/Tris-HCl (80:20, volume/volume, $\mathrm{pH} 7.80 .2 \mathrm{M}$ ) for 1 minute. The samples remained at repose for 1 hour, protected from light. Then, they were centrifuged for 15 minutes at $3500 \mathrm{rpm}$ and the supernatants were immediately taken to be read in spectrophotometer (B422 model, Micronal) in visible region at 537 nanometers (anthocyanins). The acetone/tris-HCl solution was used as blank sample. The absorbance values were converted to $\mathrm{mg} / 100 \mathrm{~g}$ of blackberry pulp solids. 


\subsubsection{Statistical analysis}

Significant differences between average results were evaluated by analysis of variance (ANOVA) and Tukey test at 5\% of level of significance, using SAS software (Cary, NC, USA).

\section{Results and discussion}

Microencapsulated blackberry pulp were successfully obtained by spray drying and freeze drying techniques, using a mixture of arrowroot starch and gum arabic as encapsulating agents. However, spray drying of blackberry pulp without encapsulating agent was not possible. There is great difficulty in drying fruit pulps by spray drying method without addition of encapsulating agent, since fruits are rich in low molecular weight sugars, which have low glass transition temperatures and influence transition temperature of dried particles, hindering drying process by this method. With addition of encapsulating agent, the end glass transition temperature of the pulp and agents mixture tends to increase, reducing stickiness of pulp by microencapsulation and, consequently, decreasing its adhesion in drying chamber, making possible to collect the powder. [14]

The powders presented blackberry characteristic sweet aroma and reddish color. The results of characterization of freeze dried blackberry pulp (BL), microencapsulated freeze dried blackberry pulp (ML) and microencapsulated spray dried blackberry pulp (MS) powders are shown in Table 1. The yield of freeze drying process was significantly $(p<0.05)$ higher than value found by spray drying. In spray drying method, losses are due to the material adhered to drying chamber and cyclone, which is generally not suitable for use. Blackberry powders with encapsulating agent (ML and MS) presented significant water contents ( $\mathrm{p}$ $<0.05$ ), lower than the non-encapsulating blackberry (BL) powder. The water activity values for all powders was below 0.3 , indicating their microbiological stability (Aw $<0.3$ ). Particles of ML and ML powders were significantly $(\mathrm{p}<0.05)$ higher than MS powder particles and, although $\mathrm{BL}$ and $\mathrm{ML}$ powders were produced by the same method, $\mathrm{ML}$ powder particles were significantly $(p<0,05)$ smaller than BL powder particles, without encapsulant. The presence of encapsulating agent and the type of method used to produce the powders influenced the average particle diameter of powders. The size of spray particles is directly influenced by the size of spray droplets. Size of these droplets is dependent on type of atomizer and physical properties such as atomizer rotation, atomizer pressure and solution solids concentration.[15] The size of particles produced by freeze drying is a consequence of type of milling and its operating conditions. 
Blackberry pulp microencapsulation with arrowroot starch and gum arabic mixture by spray drying and freeze drying

Table 1. Characterization of freeze dried blackberry pulp $(B L)$, microencapsulated freeze dried blackberry pulp (ML) and spray dried microencapsulated blackberry pulp (MS) powders.

\begin{tabular}{|c|c|c|c|}
\hline Analysis & $\begin{array}{l}\text { Powder of } \\
\text { freeze dried } \\
\text { blackberry } \\
\text { pulp (BL) }\end{array}$ & $\begin{array}{c}\text { Freeze dried } \\
\text { microencapsulated } \\
\text { blackberry pulp } \\
\text { (ML) }\end{array}$ & $\begin{array}{c}\text { Spray dried } \\
\text { microencapsulated } \\
\text { blackberry pulp } \\
\text { (MS) }\end{array}$ \\
\hline Process yield (\%) & $\begin{array}{l}89.24 \pm \\
2.81 A^{*}\end{array}$ & $95.86 \pm 0.89 \mathrm{~A}$ & $57.69 \pm 8.97 \mathrm{~B}$ \\
\hline Moisture content (\%) & $10.72 \pm 2.81 \mathrm{~A}$ & $4.50 \pm 0.31 \mathrm{~B}$ & $1.30 \pm 0.10 \mathrm{~B}$ \\
\hline Aw (decimal) & $0.13 \pm 0.01 \mathrm{~B}$ & $0.11 \pm 0.01 \mathrm{~B}$ & $0.16 \pm 0.02 \mathrm{~A}$ \\
\hline Mean diameter D [4.3] ( $\mu \mathrm{m})$ & $\begin{array}{c}149.50 \pm \\
2.92 \mathrm{~A}\end{array}$ & $95.96 \pm 5.87 \mathrm{~B}$ & $9.82 \pm 0.12 \mathrm{C}$ \\
\hline $\begin{array}{l}\text { Hygroscopicity (g of } \\
\text { adsorbed water / } 100 \mathrm{~g} \\
\text { solids) }\end{array}$ & $21.28 \pm 0.45 \mathrm{~A}$ & $12.86 \pm 0.14 \mathrm{C}$ & $17.04 \pm 0.30 \mathrm{~B}$ \\
\hline Solubility in water (\%) & $61.26 \pm 0.49 \mathrm{~A}$ & $53.84 \pm 0.76 \mathrm{~B}$ & $60.16 \pm 0.60 \mathrm{~A}$ \\
\hline Wettability (min) & $0.99 \pm 0.53 B$ & $1.66 \pm 0.01 \mathrm{~B}$ & $9.77 \pm 0.22 \mathrm{~A}$ \\
\hline $\begin{array}{l}\text { Total Anthocyanins (mg / } \\
100 \text { g of blackberry solids) }\end{array}$ & $\begin{array}{c}125.27 \pm \\
9.77 \mathrm{~A}\end{array}$ & $125.99 \pm 5.25 \mathrm{~A}$ & $86.35 \pm 3.37 \mathrm{~B}$ \\
\hline
\end{tabular}

*Same letters in the same line show no statistical difference ( $\mathrm{p}>0.05)$.

BL powder was shown to be more hygroscopic and more water soluble than powders produced with encapsulating agent. Arrowroot starch and gum arabic used as encapsulants have low hygroscopicity. Accordingly, microencapsulation of blackberry pulp tends to reduce the hygroscopicity of resulting powder. Moreover, although gum arabic is highly soluble in water [16], arrowroot starch in its native form has low solubility in water at room temperature, which probably contributed to decrease the solubility of the blackberry powders. This behavior indicates that the blackberry pulp was actually microencapsulated by the arrowroot starch and gum arabic mixture and by both methods.

The wettability of freeze drying powders (BL and ML) were significantly $(p<0.05)$ lower than the value found for spray dried powder. This occurred because powders obtained by freeze drying presented larger particle size (Table 1). Particles of larger sizes have more spaces between them, being more easily penetrated by water.[2] On the other hand, powder particles obtained by spray drying were much smaller and less porous. This led to a larger formation of lumps when they came into contact with water. The low wettability of very 
fine powders is due to their high surface tension and the viscous layer formed on the surface of the liquid that prevents capillary flow between the intergranular pores.[17] Concerning the anthocyanin content, freeze dried blackberry powders (BL and ML) presented values significantly $(p<0.05)$ higher than spray drying (MS) powder. The bioactive compounds losses in spray drying process are related to the large air exposed surface [18] and high temperatures, whereas the loss during freeze drying is associated with the grinding of the material after lyophilization.[19]

\section{Conclusions}

Freeze drying and spray drying methods were successfully used for powder microencapsulation of blackberry pulp (ML and MS) and only freeze drying method was able to dry blackberry pulp (BL) without encapsulant. The yield of the freeze dried blackberry drying process powders was significantly $(p<0.05)$ higher than the value found for spray drying process. Blackberry powders was microbiological stability. The presence of encapsulating agent and the type of method used to produce the powders influenced in physical chemical characteristics of the powders.

\section{References}

[1] Machado, A.P.F.; Pasquel-Reátegui, J.L.; Barbero, G.F., Martínez, J. Pressurized liquid extraction of bioactive compounds from blackberry (Rubus fruticosus L.) residues: a comparison with conventional methods. Food Research International 2015, 77, 675-683.

[2] Ferrari, C.C.; Ribeiro, C.P.; Aguirre, J.M. Spray drying of blackberry pulp using maltodextrin as carrier agent. Brazilian Journal of Food Technology 2012, 15, 157165.

[3] Gharsallaoui, A.; Roudaut, G.; Chambin, O.; Voilley, A.; Saurel, R. Applications of spray-drying in microencapsulation of food ingredients: An overview, Food Research International 2007, 40, 1107-1121.

[4] Yamashita, C.; Chung, M.M.S.; dos Santos, C.; Mayer, C.R.M.; Moraes, I.C.F.; Branco, I.G. Microencapsulation of an anthocyanin-rich blackberry (spp.) by-product extract by freeze-drying. LWT - Food Science and Technology 2017, 84, 256-262.

[5] Ré, M.I. Microencapsulation by spray drying. Drying Technology 1998, 16, 11951236.

[6] Villas-Boas, F.; Franco, C.M.L. Effect of bacterial $\beta$-amylase and fungal $\alpha$-amylase on the digestibility and structural characteristics of potato and arrowroot starches. Food Hydrocolloids 2016, 52, 795- 803.

[7] Charles, A.L.; Cato, K.; Huang, T-C., Chang, Y-H.; Ciou, J-Y.; Chang, J-S; Lin, H-H. Functional properties of arrowroot starch in cassava and sweet potato composite starches. Food Hydrocolloids 2016, 53, 187-191. 
Blackberry pulp microencapsulation with arrowroot starch and gum arabic mixture by spray drying and freeze drying

[8] Mothé, C.G.; Rao, M.A. Thermal behavior of gum arabic in comparison with cashew gum. Thermochimica Acta 2000, 357-358, 9-13.

[9] A.O.A.C. Official Methods of Analysis. 18th ed. Association of Official Analytical Chemists, Gaithersburg, Maryland, 2006.

[10] Cai, Y.Z.; Corke, H. Production and properties of spray-dried Amaranthus betacyanin pigments. Journal of Food Science 2000, 65, 1248-1252.

[11] Cano-Chauca, M.; Stringheta, P.C.; Ramos, A.M.; Cal-Vidal, J. Effect of the carriers on the microstructure of mango powder obtained by spray drying and its functional characterization. Innovative Food Science and Emerging Technologies 2005, 5, 420 428.

[12] Hla, P.K., Hogekamp, S. Wetting behaviour of instanized cocoa beverage powders. International Journal of Food Science and Technology 1999, 34, 4, 335-342.

[13] Sims, D.A., \& Gamon, J.A. (2002). Relationships between leaf pigment content and spectral reflectance across a wide range of species, leaf structures and developmental stages. Remote Sensing of environment, 81, 337-354.

[14] Santana, A.; Cano-Higuita, D.M.; de Oliveira, R.A.; Telis, V.R.N. Influence of different combinations of wall materials on the microencapsulation of jussara pulp (Euterpe edulis) by spray drying. Food Chemistry 2016, 212, 1-9.

[15] Goula, A.M., Adamopoulos, K.G. Retention of ascorbic acid during drying of tomato halves and tomato pulp. Drying Technology 2006, 24, 57-64.

[16] Daza, L.D.; Fujita, A.; Fávaro-Trindade, C.S.; Rodrigues-Ract, J. N.; Granato, D.; Genovese, M. I. Effect of spray drying conditions on the physical properties of Cagaita (Eugenia dysenterica DC.) fruit extracts. Food and Bioproducts Processing 2016, 97, 20-29

[17] Schubert, H. Instantization of powdered food products. International Chemical Engineering 1993, 33, 1, 28-45.

[18] Oberoi, D.P.S.; Sogi, D.S. Effect of drying methods and maltodextrin concentration on pigment content of watermelon juice powder. Journal of Food Engineering 2015, 165, 172-78.

[19] Kuck, L.S.; Noreña, C.P.Z. Microencapsulation of grape (Vitilabrusca var. Bordo) skin phenol extract using gum arabic, polydextrose, and partially hydrolyzed guar gum as encapsulating agents. Food Chemistry 2016, 194, 569-576. 